\title{
Effects of pomegranate juice (Punica Granatum) on inflammatory biomarkers and complete blood count in patients with COVID-19: a structured summary of a study protocol for a randomized clinical trial
}

Mojtaba Yousefi ${ }^{1}$, Mohammadreza Sadriirani ${ }^{1}$, Azizollah PourMahmoudi ${ }^{1}$, Sara Mahmoodi ${ }^{1}$, Bahar Samimi ${ }^{1}$, Mahboobe Hosseinikia', Zaker Saeedinezhad ${ }^{2}$ and Seyed Bahman Panahande ${ }^{1 *}$ (D)

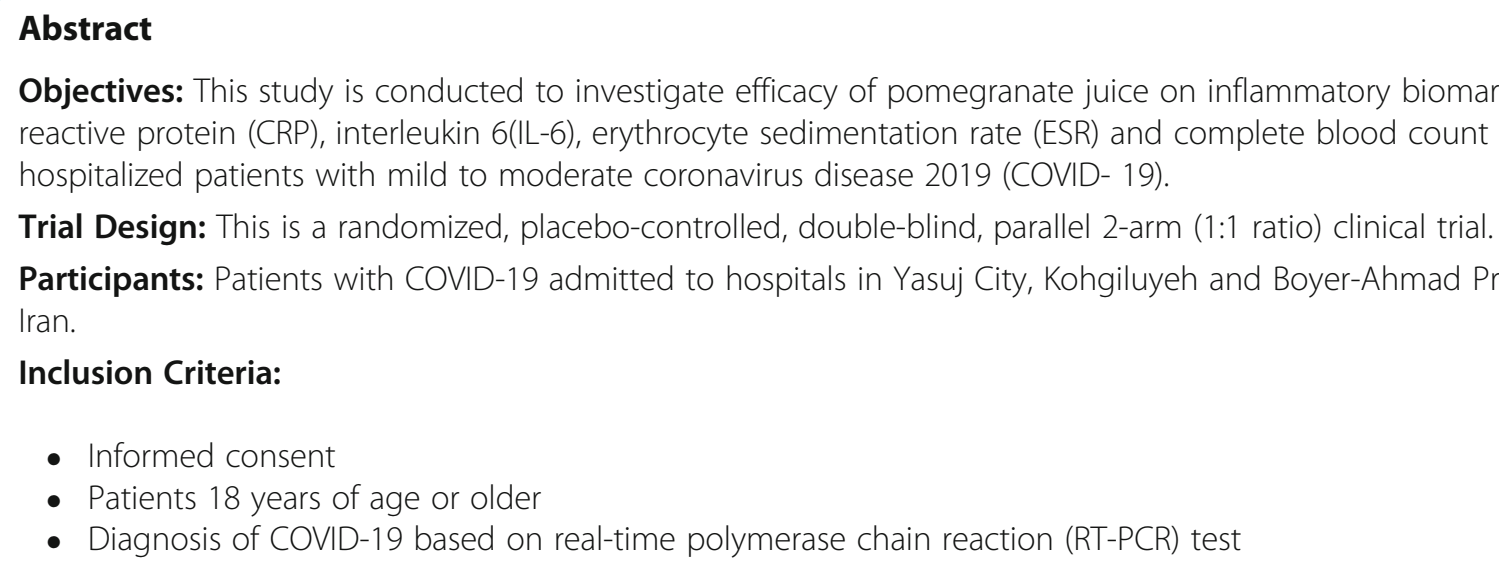
hospitalized patients with mild to moderate coronavirus disease 2019 (COVID- 19).

Trial Design: This is a randomized, placebo-controlled, double-blind, parallel 2-arm (1:1 ratio) clinical trial. Iran.

\section{Inclusion Criteria:}

- Informed consent

- Patients 18 years of age or older

- Diagnosis of COVID-19 based on real-time polymerase chain reaction (RT-PCR) test

Objectives: This study is conducted to investigate efficacy of pomegranate juice on inflammatory biomarkers, Creactive protein (CRP), interleukin 6(IL-6), erythrocyte sedimentation rate (ESR) and complete blood count (CBC) in

Participants: Patients with COVID-19 admitted to hospitals in Yasuj City, Kohgiluyeh and Boyer-Ahmad Province,

\section{Exclusion Criteria:}

- Pregnancy or lactation

- Immunoglobulin A (IgA) level $<61 \mathrm{mg} / \mathrm{dl}$

- Disseminated intravascular coagulation or any other types of coagulopathy

- Severe congestive heart failure

- Participation in any clinical trial within 30 days prior to enrollment in this RCT

- Other contraindications determined by the specialist.

(Continued on next page)

\footnotetext{
* Correspondence: panahande.b@gmail.com

'Department of Nutrition, School of Health and nutrition, Yasuj University of Medical Sciences, Yasuj, Iran

Full list of author information is available at the end of the article
}

C C The Author(s). 2021 Open Access This article is licensed under a Creative Commons Attribution 4.0 International License, which permits use, sharing, adaptation, distribution and reproduction in any medium or format, as long as you give appropriate credit to the original author(s) and the source, provide a link to the Creative Commons licence, and indicate if changes were made. The images or other third party material in this article are included in the article's Creative Commons licence, unless indicated otherwise in a credit line to the material. If material is not included in the article's Creative Commons licence and your intended use is not permitted by statutory regulation or exceeds the permitted use, you will need to obtain permission directly from the copyright holder. To view a copy of this licence, visit http://creativecommons.org/licenses/by/4.0/. The Creative Commons Public Domain Dedication waiver (http://creativecommons.org/publicdomain/zero/1.0/) applies to the data made available in this article, unless otherwise stated in a credit line to the data. 
(Continued from previous page)

Intervention and Comparator: Intervention: $500 \mathrm{ml}$ pomegranate juice and standard of care hospital treatment for COVID-19

Comparator: matching placebo containing $500 \mathrm{ml}$ of red water and standard of care hospital treatment for COVID19

Both intervention and comparator to be taken twice a day, after lunch and dinner, for 14 days.

\section{Criteria for Discontinuing:}

Transfer of patients to intensive care unit (ICU)

Death

Unwillingness to continue participating in the study

Main Outcomes: The main outcomes of this study are levels of inflammatory biomarkers, CRP, IL-6, ESR, and CBC after 14 days of treatment.

Randomization: Eligible patients will be randomly assigned into the intervention or control group in a 1:1 ratio. Randomization will be performed based on 8 permuted blocks with block sizes of 6 and they will be stratified according to sex and age categories. Randomization sequences will be prepared by the trial's pharmacist using computer-generated random numbers.

Blinding (Masking): This study is a double-blind clinical trial (participant, researcher). The pomegranate juice and placebo juice are packaged in identical bottles, and the researcher and all the patients will be unaware of the study assignment until the end of the study. To ensure blinding, the randomization sequences will be kept in identical, opaque, sealed, and sequentially numbered envelopes.

Numbers to Be Randomized (Sample Size): The calculated total sample size is 48 patients, with 24 patients assigned into each group.

Trial Status: The protocol is Version 1.0, on March 3, 2021. Recruitment started on February 28, 2021, and is anticipated to be completed by May 21, 2021.

Trial Registration: The Name of registering trial

Effects of Pomegranate Juice (Punica Granatum) on Inflammatory Biomarkers and CBC in Patients with COVID-19: A Randomized, Double-Blind, Placebo-Controlled Clinical Trial.

Iranian registry of clinical trials (IRCT) Registration Number: IRCT20150711023153N2

Date of Trial Registration

February 28, 2021, retrospectively registered

Full Protocol: The full protocol is attached as an additional file, accessible from the Trials ${ }^{-}$website (Additional file 1). In the interest of expediting dissemination of this material, the familiar formatting has been eliminated; this Letter serves as a summary of the key elements of the full protocol.

Keywords: COVID-19, Randomized Controlled Trial, Protocol, Pomegranate Juice, CRP, IL-6, CBC, ESR

\section{Supplementary Information}

The online version contains supplementary material available at https://doi. org/10.1186/s13063-021-05194-9.

Additional file 1.

\section{Acknowledgements}

The authors would like to thank the Yasuj University of Medical Sciences for supporting the present research on COVID-19.

\section{Authors' contributions}

SBP is the Chief Investigator; he conceived the study. SBP and MY led the proposal and protocol development. MY, MRSI, BS, SM and ZS are contributing to data collection, study design and to development of the proposal. SBP and MY are revising the manuscript. MH and AP contributed to statistical interpretations. All authors read and approved the final manuscript.

\section{Funding}

This study was funded and supported by Yasuj University of Medical Sciences, Yasuj, Kohgiluyeh and Boyer-Ahmad Province, Iran. The funders did not have a role in the design of the study, the intervention, collection, analysis, interpretation of data and writing the manuscript

\section{Availability of data and materials}

The final dataset of the trial will be available upon request from the primary investigator via e-mail at panahande.b@gmail.com, after obtaining permission from the Regional Ethics Committee.

\section{Declarations}

\section{Ethics approval and consent to participate}

The present trial was approved by the Ethics Committee of Yasuj University of Medical Sciences (Ethics Committee Reference Number:

IR.YUMS.REC.1399.181) on January 20, 2021. The investigators declare that the trial has received ethical approval from the appropriate ethics committee, as described above. Informed written consent will be obtained from all the participants, prior to randomization. 


\section{Consent for publication}

Not applicable.

\section{Competing interests}

The authors declare that they have no competing interests.

\section{Author details}

'Department of Nutrition, School of Health and nutrition, Yasuj University of Medical Sciences, Yasuj, Iran. ${ }^{2}$ Department of Internal Medicine, School of

Medicine, Yasuj University of Medical Sciences, Yasuj, Iran.

Received: 13 March 2021 Accepted: 15 March 2021

Published online: 02 April 2021

\section{Publisher's Note}

Springer Nature remains neutral with regard to jurisdictional claims in published maps and institutional affiliations.

Ready to submit your research? Choose BMC and benefit from:

- fast, convenient online submission

- thorough peer review by experienced researchers in your field

- rapid publication on acceptance

- support for research data, including large and complex data types

- gold Open Access which fosters wider collaboration and increased citations

- maximum visibility for your research: over $100 \mathrm{M}$ website views per year

At $\mathrm{BMC}$, research is always in progress. 